\title{
Contrast Extravasation into the Right Upper Extremity
}

\author{
Kip Mihara, M.D. ${ }^{1,2}$ and Ganesh Devendra, M.D. ${ }^{1}$ \\ 'Department of Medicine, University of California San Francisco, San Francisco, CA, USA; ${ }^{2}$ VA Hospital, San Francisco, CA, USA.
}

KEY WORDS: contrast extravasation; hyaluronidase.

$\mathrm{J}$ Gen Intern Med 30(4):531

DOI: $10.1007 / \mathrm{s} 11606-014-3120-6$

(C) Society of General Internal Medicine 2014

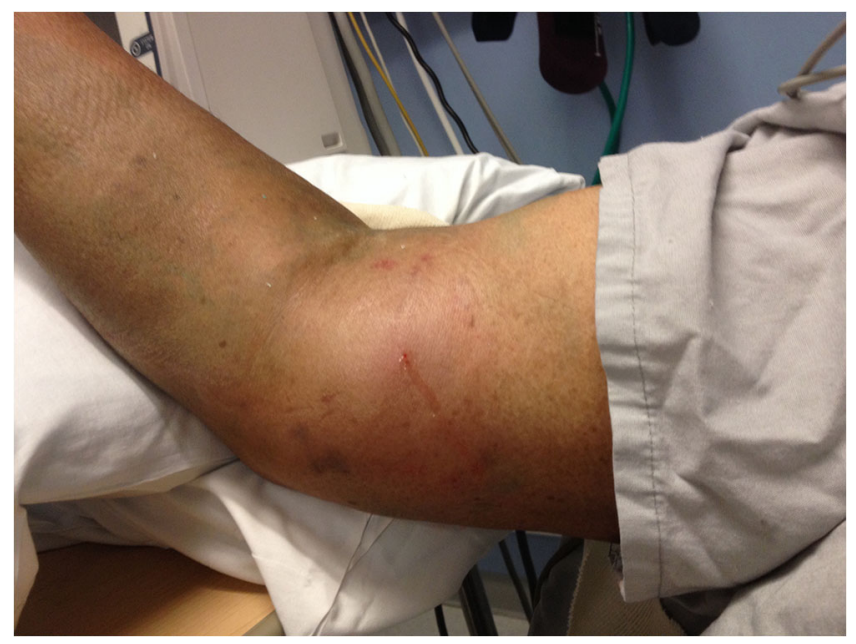

Figure 1. Right upper extremity with localized swelling.

A 76-year-old man with an esophageal diverticulum preA sented for computed tomography (CT) of the neck. During the CT scan, the deep brachial intravenous access site infiltrated with extravasation of approximately $100 \mathrm{cc}$ of iodinated contrast into the right upper extremity, associated with localized pain. Examination after the infusion demonstrated induration and swelling of the arm without neurovascular compromise (Fig. 1). A scout radiograph performed with the CT demonstrated radio-opaque material surrounding the biceps muscle (Fig. 2). The plastic surgery consultant recommended conservative management, and the patient was discharged with warm compresses and arm elevation.

Contrast extravasation occurs in $<1 \%$ of CT scans. ${ }^{1,2}$ Most cases involve small volumes, and feature self-limited pain and swelling, ${ }^{1}$ but extravasation rarely leads to skin blistering, tissue necrosis or compartment syndrome. ${ }^{3,4}$ Management involves prompt cessation of the infusion, extremity elevation and application of compresses. ${ }^{5}$ In cases with neurovascular compromise, immediate surgical decompression is recommended. ${ }^{3}$ For large volume extravasations, localized subcutaneous hyaluronidase

Received August 23, 2014

Revised October 20, 2014

Accepted November 13, 2014

Published online December 13, 2014

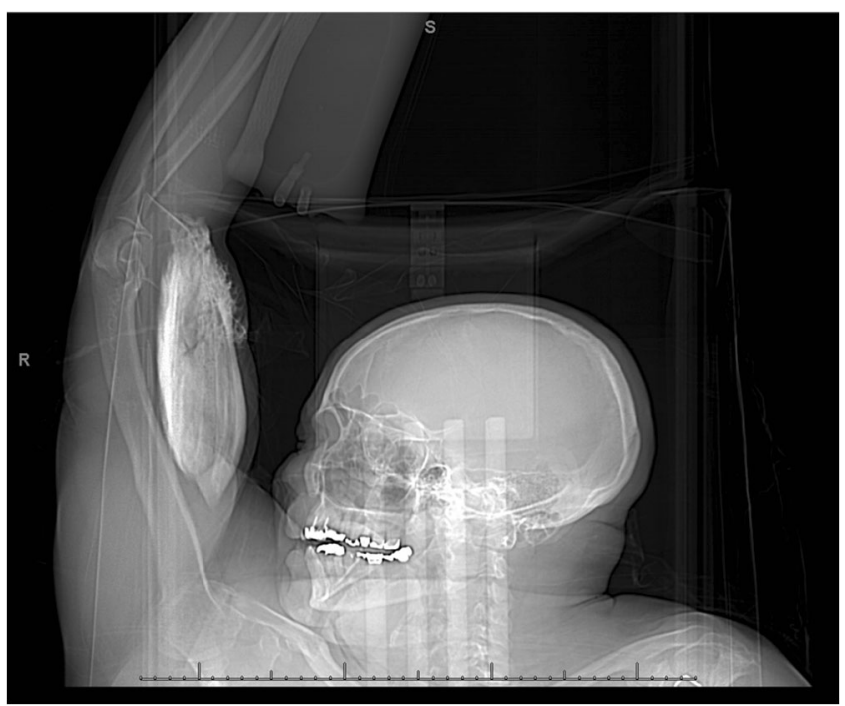

Figure 2. CT scout film demonstrating extravasation of contrast into the proximal right upper extremity.

injections can be considered, which hydrolyze glycosaminoglycans in the extracellular matrix of connective tissue, transiently increasing the permeability of the tissue. The increased permeability allows for the diffusion of extravasated materials back into the vascular bed, thereby alleviating compartment pressure. ${ }^{5}$

Conflict of Interest: The authors declare that they do not have a conflict of interest.

Corresponding Author: Ganesh Devendra, M.D.; Department of MedicineUniversity of California San Francisco, San Francisco, CA, USA (e-mail: ganesh.devendra@ucsf.edu).

\section{REFERENCES}

1. Sbitany H, Koltz PF, Mays C, Girotto JA, Langstein HN. CT contrast extravasation in the upper extremity: strategies for management. Int J Surg. 2010;8(5):384-386.

2. Hawi N, Citak M, Liodakis E, Petri M, Haasper C, Krettek C, Meller R. [Development of compartment syndrome after intravenous administration of an X-ray contrast medium. Recommendations on acute therapy regimens]. Unfallchirurg. 2014;117(4):374-379.

3. Yurdakul E, Salt O, Durukan P, Duygulu F. Compartment syndrome due to extravasation of contrast material: a case report. Am J Emerg Med. 2014;1155(9):e3-5.

4. Selek H, Ozer H, Aygencel G, Turanli S. Compartment syndrome in the hand due to extravasation of contrast material. Arch Orthop Trauma Surg. 2007; 127(6):425-427.

5. Rowlett J. Extravasation of contrast media managed with recombinant human hyaluronidase. Am J Emerg Med. 2012;30(9):e2101-2103. 